\title{
Identifying Key Factors for Introducing GPS-Based Fleet Management Systems to the Logistics Industry
}

\author{
Yi-Chung Hu, Yu-Jing Chiu, Chung-Sheng Hsu, and Yu-Ying Chang \\ Department of Business Administration, Chung Yuan Christian University, Chung Li District, Taoyuan City 32023, Taiwan \\ Correspondence should be addressed to Yu-Jing Chiu; yujing@cycu.edu.tw
}

Received 21 November 2014; Accepted 2 February 2015

Academic Editor: Jinhu Lü

Copyright ( $) 2015$ Yi-Chung Hu et al. This is an open access article distributed under the Creative Commons Attribution License, which permits unrestricted use, distribution, and reproduction in any medium, provided the original work is properly cited.

\begin{abstract}
The rise of e-commerce and globalization has changed consumption patterns. Different industries have different logistical needs. In meeting needs with different schedules logistics play a key role. Delivering a seamless service becomes a source of competitive advantage for the logistics industry. Global positioning system-based fleet management system technology provides synergy to transport companies and achieves many management goals such as monitoring and tracking commodity distribution, energy saving, safety, and quality. A case company, which is a subsidiary of a very famous food and retail conglomerate and operates the largest shipping line in Taiwan, has suffered from the nonsmooth introduction of GPS-based fleet management systems in recent years. Therefore, this study aims to identify key factors for introducing related systems to the case company. By using DEMATEL and ANP, we can find not only key factors but also causes and effects among key factors. The results showed that support from executives was the most important criterion but it has the worst performance among key factors. It is found that adequate annual budget planning, enhancement of user intention, and collaboration with consultants with high specialty could be helpful to enhance the faith of top executives for successfully introducing the systems to the case company.
\end{abstract}

\section{Introduction}

The rise of e-commerce and globalization has changed consumption patterns. Different industries have different logistical needs. In meeting needs for small, diverse, and highfrequency pickups and deliveries at different locations, in different packaging and according to different schedules and in determining how different operations such as purchasing, manufacturing, warehousing, distribution, and management contribute to a good solution, logistics play a key role. Delivering a seamless service has become a source of competitive advantage for the logistics industry. Fleet management systems (FMS) have been available in the logistics industry for many years. Crainic and Laporte $[1,2]$ pointed out that first-generation FMS provided relatively simple functionalities such as vehicle tracking components. With increased management sophistication, these systems have evolved into planning tools [3, 4]. In addition, fleet management involves supervising the use and maintenance of vehicles and associated administrative functions, including coordination and dissemination of tasks and related information to solve the heterogeneous scheduling and vehicle routing problem [5]. For vehicle fleet management and monitoring, one of the main applications is the global positioning system (GPS) technology $[6,7]$. GPS-based fleet management system technology has provided synergy to transport companies and has achieved many management goals such as monitoring and tracking commodity distribution, energy savings, safety, and quality. A fleet management system is a complex network to manage and control. It is well known that most real-world management systems are typical complex and evolving networks [8-11], and fleet management systems are no exception.

This research used the $\mathrm{P}$ Transport Company as an empiricalstudy case. The company, which operates the largest shipping line in Taiwan, is a subsidiary of a famous food and retail conglomerate, which is the largest group of chain stores in Taiwan. The system had to serve the country's largest logistics system and provide comprehensive logistical support, and fast supply to all outlets nationwide. The $\mathrm{P}$ Transport Company was committed to continuously enhance 
the competitiveness by the introduction of GPS. Although the P Transport Company worked energetically to implement intelligent fleet management systems, these have not been successful in recent years. The P Transport Company was in the system implementation phase at the time of this research and wanted to avoid another failure in introducing a fleet management system. After interviewing the managers of P Transport Company, four main reasons for earlier failures were identified: organizational resistance to change, ongoing information technology innovation, lack of professional training and experience in project staff, and multiple customer patterns and complex operating procedures.

This research intended to identify the key factors in introducing GPS-based fleet management systems to the logistics industry by the analysis of P Transport Company. For the purpose of this paper, several factors were involved, and it was necessary to determine which of these factors was the most significant for achieving the objective of this study. In addition, this complex management problem was a classic case of multiple-criteria decision-making (MCDM), and these indicators had interdependent impacts. Regarding the research methods, analytic network process (ANP) is a widely used method that considers interdependencies among factors and determines their relative importance [12-16]. A combination of Decision-Making Trial and Evaluation Laboratory (DEMATEL) and ANP has been widely used to solve various decision problems [17-20]. To take interdependencies into consideration and determine the key factors, this paper incorporates a novel combination of DEMATEL and ANP into the study. By analyzing the case company, this study contributes to explore an important issue that identifies key factors for introducing GPS-based fleet management systems to the logistics industry using DEMATEL and ANP.

The results showed that support from executives was the most important criterion and had profound influence on other criteria. Performance on other key factors was improved if corporate executives showed strong support. The other key factors were user recognition, funding and budget, project team composition, correct information in real time, and degree of completion of transmission equipment. The proposed model was implemented in a transport company in Taiwan. Based on the results obtained, it was suggested that transport companies and the logistics industry introduce GPS-based fleet management systems, which will increase their chance of success.

Section 1 of this paper provides an introduction which summarizes the research motive, purpose, methodology, and study results. Section 2 provides a brief review of GPS-based fleet management systems and key factors for introducing these systems. Section 3 describes the methodology used and Section 4 presents an example and results. Finally, conclusions and recommendations can be found in Section 5.

\section{Literature Review}

2.1. Fleet Management Systems and GPS. Intelligent transportation systems (ITS) were defined in [21] as using information technologies, computers, and communications in transportation systems to solve transportation problems. These systems increase transportation efficiency, promote driving safety, improve people's lives, and raise industrial productivity [22]. Fleet management systems (FMS) have been available in the industrial domain, such as the transport business, for many years. Currently, these systems have evolved into complete enterprise management tools linking together all parts of the business. The new trend clearly dictates increased management sophistication in terms of turning these tools into planning tools $[3,4]$. They now include real-time asset management focusing on current fleet locations and prediction of planned tasks. These systems today offer a broad range of functionalities, including tight integration with internal enterprise resource planning (ERP) systems and systems located at customer sites. Specifically, extensive use of realtime data and wireless communications serve together with increased intelligence for real-time planning, where industry developers identify these parameters as the primary drivers for current developments [23].

In an industrial context, a complete logistics system involves transporting raw materials from a number of suppliers, delivering them to the factory for processing, transporting the products to different depots, and finally distributing them to customers [5]. In this case, transportation for both supply and distribution requires effective management procedures to optimize routes and costs. These procedures form part of the overall supply-chain management of the company [24]. The American Heritage Dictionary defines a global positioning system as "A system for determining a position on the Earth's surface by comparing radio signals from several satellites. Depending on your geographic location, the GPS receiver samples data from up to six satellites; it then calculates the time taken for each satellite signal to reach the GPS receiver, and from the difference in time of reception, determines your location [25]" A number of literatures have been published which provide information to engineers about GPS technology applications to transportation systems, especially to intelligent transportation systems [26, 27].

GPS became very important because not only did the military rely on them to provide navigation, but the public sector did as well. These devices were used by pilots, miners, mountain climbers, and many others working in dangerous occupations [28]. Several industries such as the logistics realized this and started to focus on research and quality control. These industries also realized the benefit of combining GPS technology with telecommunications. This enabled GPS receivers to transmit data to a base station for analysis. Another advance was a GPS architecture that enabled integration of the technology into computers and other devices. This opened up a huge spectrum of uses for GPS [28]. Companies can reduce costs and create greater customer satisfaction by implementing GPS systems as part of already established processes [28]. GPS became a "tool of the trade" in trucking companies for logistics management.

GPS devices gave managers more accurate estimates of both the time of arrival and the time of delivery of goods to the customer [29]. As part of logistics management, fleet management can be a practical tool for managing a vehicle fleet to improve scheduling, operating efficiency, and effectiveness [30]. In addition, fleet management involves 
TABLE 1: Aspects for the introduction of management information systems.

\begin{tabular}{ll}
\hline Aspects & Descriptions \\
\hline Organization & $\begin{array}{l}\text { The impact of implementing a system in an organization: the system must be } \\
\text { accepted by the organization and integrated into the workflow among other existing } \\
\text { information systems. Staff can have concerns arising from the nature of the } \\
\text { organizational change resistance mentality. }\end{array}$ \\
\hline The execution and management of the project: IT project management must usually \\
work with a series of complex problems and diverse staff. In particular, team \\
management requires a high degree of expertise to deal with project execution \\
management issues.
\end{tabular}

supervising the use and maintenance of vehicles and associated administrative functions, including coordination and dissemination of tasks and related information to solve heterogeneous scheduling and vehicle routing problems [5].

2.2. Introduction of Management Information Systems. The introduction of new systems can be understood from business experience and from the literature. A successful system introduction provides positive benefits to an organization, but a failed introduction can do harm to the organization. Many studies have focused on the key factors affecting the introduction of a new system to a company. Table 1 summarizes related aspects and literatures for the introduction of management information systems and Table 2 shows preliminary aspects and criteria cited from the related literatures.

\section{Methodology}

3.1. Delphi Method. The Delphi method is a research approach to group decision-making. Reference [31] indicated that the Delphi method depends on experts' experience, instincts, and values to determine outcomes. In this method, a group of six experts discusses a specific question, because experts from different fields can be expected to provide multiple perspectives. Besides, the experts can understand each other's perspectives in one round of the questionnaire and adjust their own perspectives in the next questionnaire round to reach consistency.

The related operations are briefly introduced as follows. First, the appropriate experts are grouped according to the nature of the question that must be decided. Hence, the number of experts is determined in terms of the dimensions, professional requirements, complexity, and scope of the problem. In general, the group will not exceed twenty people. Second, background information about the decision is transmitted to the experts, and they are asked what else they need. Furthermore, they are advised of the questions that must be answered and any related requests. Finally, the experts are asked to answer the questions in writing. Third, the experts indicate their perspectives and explain how these perspectives were obtained from the information given. Fourth, the expert perspectives are synthesized for the first time to produce an information form, which is sent to the experts so that they can understand the differences between their perspectives and those of others and adjust their perspectives and evaluation accordingly. Fifth, the major part of the Delphi method involves collecting experts' perspectives and providing feedback. In other words, the modified perspectives from the experts are collected, synthesized, and sent back to each expert for further modification. Note that each expert's name is not included when the information is fed back to the experts as a group. This process is repeated until no expert submits further modifications. Finally, the experts' perspectives are synthesized, and conclusions are presented.

3.2. DEMATEL-Based ANP (DANP). Traditionally, a network relation map (NRM) was necessary for ANP, but NRM should be acquired by other auxiliary tools. Undoubtedly, Decision-Making Trial and Evaluation Laboratory (DEMATEL) is an appropriate choice for constructing NRM [20] by describing interdependencies visually in the form of networks consisting of explainable nodes and directed arcs [31]. Nevertheless, a serious problem for ANP is that if there are too many criteria involving pairwise comparisons, 
TABle 2: Preliminary aspects and criteria for the study.

\begin{tabular}{|c|c|c|}
\hline Aspects & Criteria & Descriptions \\
\hline \multirow{4}{*}{ Organization } & Top executives support & $\begin{array}{l}\text { Executives' subjective preferences or understanding of the project, continued } \\
\text { participation, promises of funding and resources required, and removal of } \\
\text { obstacles to the project. }\end{array}$ \\
\hline & Enterprise process reengineering & $\begin{array}{l}\text { The need to change the organization's structure, responsibilities, and workflow } \\
\text { in response to the implemented system. }\end{array}$ \\
\hline & User recognition & $\begin{array}{l}\text { Whether employees have sufficient momentum to drive their participation in } \\
\text { the system. }\end{array}$ \\
\hline & Funding and budget & $\begin{array}{l}\text { The project budget for implementing software, hardware, and subsequent } \\
\text { maintenance requirements. }\end{array}$ \\
\hline \multirow{5}{*}{ Project base } & Clear objectives & $\begin{array}{l}\text { A clear understanding of importing goals and performance those are from the } \\
\text { various departments. }\end{array}$ \\
\hline & Project team composition & $\begin{array}{l}\text { Organizations with outstanding staff from ministries can take up the } \\
\text { challenge and work together to resolve difficulties. }\end{array}$ \\
\hline & $\begin{array}{l}\text { Project management and } \\
\text { monitoring }\end{array}$ & Project leaders and teams control project progress. \\
\hline & Effective communication & To resolve conflict. \\
\hline & Education and training & Actual effectiveness of education and training. \\
\hline \multirow{4}{*}{$\begin{array}{l}\text { System } \\
\text { technology }\end{array}$} & Timely and correct information & Control over correct and timely input information. \\
\hline & $\begin{array}{l}\text { Degree of difficulty in software } \\
\text { and hardware maintenance }\end{array}$ & $\begin{array}{l}\text { Degree of maintenance difficulty for system and hardware devices in the } \\
\text { future. }\end{array}$ \\
\hline & $\begin{array}{l}\text { Degree of difficulty in technology } \\
\text { setup }\end{array}$ & $\begin{array}{l}\text { Degree of difficulty in setup of system technology and extension to various } \\
\text { centers. }\end{array}$ \\
\hline & $\begin{array}{l}\text { Degree of completeness of } \\
\text { transmission equipment }\end{array}$ & Transmission performance and scalability of equipment installed in a truck. \\
\hline \multirow{3}{*}{ Consultant } & Experience of consultants & $\begin{array}{l}\text { Industrial familiarity, expressive ability, and communication skills of } \\
\text { consultants. }\end{array}$ \\
\hline & Ability of consultants & $\begin{array}{l}\text { Degree of professional competence of consultants for each module in the } \\
\text { system. }\end{array}$ \\
\hline & $\begin{array}{l}\text { Coordination and } \\
\text { communication }\end{array}$ & $\begin{array}{l}\text { Service gap between expectation and perception of customers in the } \\
\text { consultant's interaction process. }\end{array}$ \\
\hline \multirow[t]{2}{*}{$\begin{array}{l}\text { External } \\
\text { environment }\end{array}$} & Industry competitive pressure & $\begin{array}{l}\text { Development of innovation in industry is very rapid and, therefore, when } \\
\text { facing competition, a further assessment of the competitive environment } \\
\text { facing the enterprise is required. }\end{array}$ \\
\hline & Customer acceptance & Willingness of customers to implement a system and conditions imposed. \\
\hline
\end{tabular}

then the time required for pairwise comparisons increases substantially. Moreover, it is not easy to achieve consistency [32], especially for the matrix with high order, because of the influence of the limited ability of human thinking and the shortcomings of one to nine scale [33]. To solve the abovementioned problems, the so-called DANP took the total influence matrix generated by DEMATEL as the unweighted supermatrix of ANP directly to avoid troublesome pairwise comparisons. Similar to ANP, relative weights of individual factors can be obtained by generating a limiting supermatrix. Tzeng and Huang [20] introduced the complete framework of DANP.

In particular, the framework of DANP used in this paper has several distinct features compared to [20]. First, this paper considers prominences generated by DEMATEL and relative weights generated by DANP at the same time to determine key factors instead of using relative importance by DANP merely. In other words, as represented by dashed lines in
Figure 1, both DEMATEL and DANP have the power to vote for key factors. Second, we focus on the causal diagram for key factors rather than all factors. Moreover, an arc is directed from one factor to another one if the former has the greatest influence on the latter. This can simplify greatly the representation of a causal diagram and facilitate the analysis of interdependence among key factors. Besides, the causal diagram is not dependent on relation of each factor. The reason is that the greater the relation of a factor is, the greater the influence of it on another factor is not assured. Such a novel variant of the traditional DANP is briefly depicted in Figure 1.

3.2.1. Determining the Total Influence Matrix. The performance values used to represent the degree of influence of one element on another were 0 (no effect), 1 (little effect), 2 (some effect), 3 (strong effect), and 4 (certain effect). Next, the direct influence matrix $\mathbf{Z}$ was constructed using the degree 


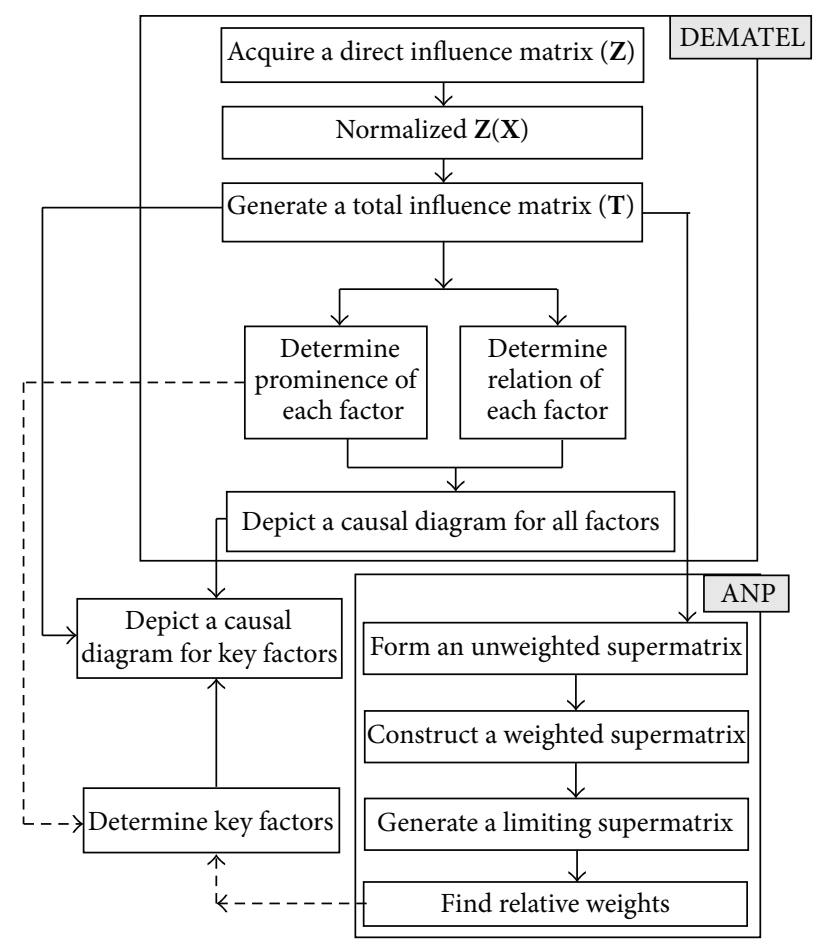

FIGURE 1: The proposed framework of DANP.

of effect between each pair of elements as obtained by the questionnaire. $z_{i j}$ represents the extent to which criterion $i$ affects criterion $j$. All diagonal elements are set to zero:

$$
\mathbf{Z}=\left[\begin{array}{cccc}
z_{11} & z_{12} & \cdots & z_{1 n} \\
z_{21} & z_{22} & \cdots & z_{2 n} \\
\vdots & \vdots & \vdots & \vdots \\
z_{n 1} & z_{n 2} & \cdots & z_{n n}
\end{array}\right]
$$

The direct influence matrix $\mathbf{Z}$ was subsequently normalized to yield a normalized direct influence matrix $\mathbf{X}$ after calculating

$$
\begin{gathered}
\lambda=\frac{1}{\max _{1 \leq i \leq n} \sum_{j=1}^{n} Z_{i j}} \quad(i, j=1,2, \ldots, n), \\
\mathbf{X}=\lambda \cdot \mathbf{Z} .
\end{gathered}
$$

The formula ( $\left.\mathbf{T}=\mathbf{X}(\mathbf{I}-\mathbf{X})^{-1}\right)$ was used to represent the total influence matrix $\mathbf{T}$ after normalizing the direct influence matrix. In this step, $\mathbf{O}$ was the zero matrix and $\mathbf{I}$ the identity matrix:

$$
\begin{gathered}
\lim _{K \rightarrow \infty} \mathbf{X}^{K}=0, \\
T=\lim _{x \rightarrow \infty}\left(\mathbf{X}+\mathbf{X}^{2}+\cdots+\mathbf{K}^{k}\right)=\mathbf{X}(\mathbf{I}-\mathbf{X})^{-1} .
\end{gathered}
$$

The total influence matrix $\mathbf{T}$ was viewed as an unweighted supermatrix and was used to normalize the total influence matrix to obtain the weighted matrix $\mathbf{W}$ for ANP. Finally, $\mathbf{W}$ was multiplied by itself several times until convergence to obtain the limiting supermatrix $\mathbf{W}^{*}$ and the global weight of all elements. Below, a simple example is used to illustrate the abovementioned operations with respect to factors $A, B, C$, and $D$ for a decision problem. Let a direct influence matrix $\mathbf{Z}$ be obtained as follows:

$$
\mathbf{Z}=\begin{gathered}
A \\
B \\
C \\
D
\end{gathered}\left(\begin{array}{llll}
A & B & C & D \\
0 & 2 & 2 & 2 \\
3 & 0 & 2 & 1 \\
3 & 1 & 0 & 2 \\
3 & 2 & 2 & 0
\end{array}\right)
$$

This matrix was subsequently normalized to obtain the normalized relation matrix $\mathbf{X}$. Then the total influence matrix $\mathbf{T}$ was calculated using $\mathbf{X}(\mathbf{I}-\mathbf{X})^{-1}$ :

$$
\begin{aligned}
& \mathbf{X}=\begin{array}{c}
A \\
B \\
C \\
D
\end{array}\left(\begin{array}{cccc}
A & B & C & D \\
0.000 & 0.233 & 0.279 & 0.233 \\
0.337 & 0.000 & 0.198 & 0.116 \\
0.326 & 0.116 & 0.000 & 0.244 \\
0.337 & 0.198 & 0.198 & 0.000
\end{array}\right)
\end{aligned}
$$

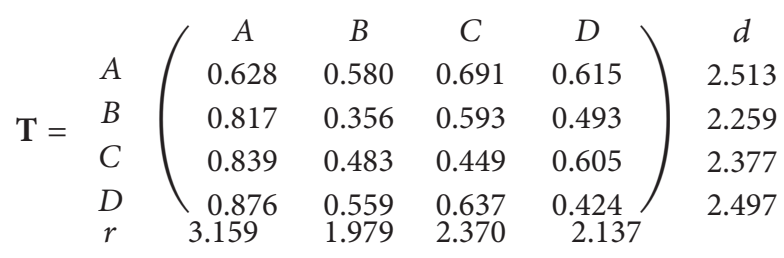

Each row of the total influence matrix was summed to obtain the value of $d$, and each column of the total influence matrix was summed to obtain the value of $r$. Hence, the sum of every row plus the sum of every column (i.e., $d+r$ ), called the prominence, shows the relational intensity of the element in question. The greater the prominence becomes, the greater the degree of importance will be among factors. The sum of every row minus the sum of every column $(d-r)$ is called the relation. If the relation is positive, then the element is inclined to affect other elements actively and was referred to as a cause. If the relation is negative, the element is inclined to be affected by other elements and was referred to as an effect. In other words, a positive relation means the degree to which such a factor affected the others is inclined to be stronger than the degree to which it was affected [17] (see Table 3).

The total influence matrix was then normalized to obtain the weighted supermatrix W (see Table 4).

Finally, W was multiplied by itself several times until convergence to obtain the limiting supermatrix $\mathbf{W}^{*}$. Factors $B, C$, and $D$ can be categorized into a class of "cause." It is worthy to mention that, although the relation of factor $D$ is the most positive (i.e., 0.3598), it has not the greatest influences on factors $A, B$, and $C$. For instance, factor $A$, which can be categorized into a class of "effect," imposes the greatest influence on factor $C$ (i.e., 0.691) rather than $D$ (i.e., 0.637). 
TABLE 3

\begin{tabular}{lccccc}
\hline Factor & $d$ & $r$ & $d+r$ & Ranking & $d-r$ \\
\hline$A$ & 2.513 & 3.159 & 5.673 & 1 & -0.6462 \\
$B$ & 2.259 & 1.979 & 4.238 & 4 & 0.2796 \\
$C$ & 2.377 & 2.370 & 4.746 & 2 & 0.0068 \\
$D$ & 2.496 & 2.137 & 4.633 & 3 & 0.3598 \\
\hline
\end{tabular}

TABLE 4

\begin{tabular}{ccccc}
\hline & $A$ & $B$ & $C$ & $D$ \\
\hline$A$ & 0.199 & 0.293 & 0.291 & 0.288 \\
$B$ & 0.259 & 0.180 & 0.250 & 0.231 \\
$C$ & 0.266 & 0.244 & 0.190 & 0.283 \\
$D$ & 0.277 & 0.283 & 0.269 & 0.199 \\
\hline
\end{tabular}

3.2.2. Identifying Key Factors. Following the simple example in the previous subsection, the comparative weights of elements $A, B, C$, and $D$ were determined as $0.266,0.231,0.246$, and 0.256 , respectively. However, it can be seen that the rankings of the importance for factors resulting from prominences generated by DEMATEL and relative weights obtained by DANP were inconsistent. In our opinion, since both DEMATEL and DANP provide partial messages regarding the selection of key factors, decisions on key factors should not be based on prominences generated by DEMATEL or relative weights obtained by DANP as the sole consideration. This motivates us to use the abovementioned message to determine the final importance rankings of factors. The overall rankings for factors are shown in Table 5 by arranging the sum of rankings of each factor in ascending order.

3.2.3. Depicting the Causal Diagram for Key Factors. Following the previous subsection, we can depict a causal diagram for key factors. For example, because factors $A, C$, and $D$ were key factors, the total influence matrix was used to draw a causal diagram. The total influence matrix showed that the factors affecting $A, C$, and $D$ most strongly were still $A, C$, and $D$ (see Figure 2).

Then, a causal diagram with respect to factors $A, C$, and $D$ can be easily depicted as shown in Figure 3 .

As shown in the causal diagram, interactions existed between factors $A, C$, and $D$. Moreover, it is reasonable for managers to get down to performance improvement of $A$ or $D$ for the problem energetically. For $A$, performance improvement of $A$ can facilitate those of $C$ and $D$. However, since $A$ is categorized into a class of "effect," the performance of $D$ is usually undertaken to improve at first to promote the performance improvement of the other key factors. We think that whether $A$ can be taken as a starting point or not should be dependent on the real situation. That is, "cause" or "effect" is just for reference. The importance-performance analysis (IPA) formulated by Martilla and James [34] can be an appropriate tool to help users examine key factors that are necessary to be improved.
TABLE 5

\begin{tabular}{lcccc}
\hline Factors & DEMATEL & DANP & $\begin{array}{c}\text { Sum of } \\
\text { rankings }\end{array}$ & $\begin{array}{c}\text { Overall } \\
\text { rankings }\end{array}$ \\
\hline$A$ & 1 & 1 & 2 & 1 \\
$B$ & 4 & 4 & 8 & 4 \\
$C$ & 2 & 3 & 5 & 2 \\
$D$ & 3 & 2 & 5 & 2 \\
\hline
\end{tabular}

We can take factors $A, C$, and $D$ as key factors.

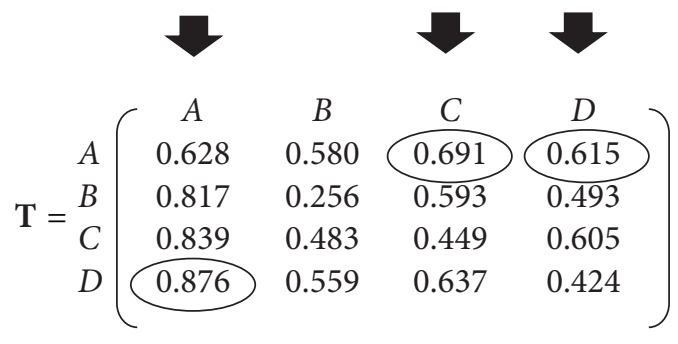

FIGURE 2

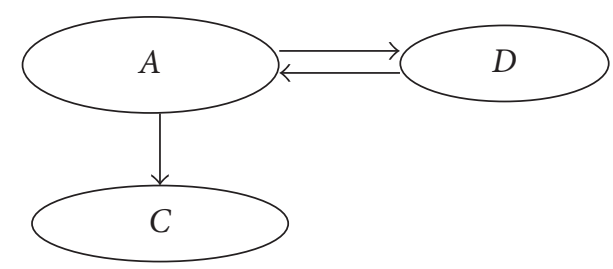

FIGURE 3

\section{Empirical Study}

4.1. Case Introduction. P Transport Company, a company owned by a large corporation, operates the largest freight transportation line in Taiwan. Their fleet consists of 1,700 trucks and is capable of serving more than 5000 retail stores. The company was beginning to introduce electronic operations and systems to enhance its competitiveness in the industry and to achieve the goals given by the corporation, in the hope that these systems would lead to higher corporate operating efficiency. However, the results were often unsatisfactory. P Transport Company's recent attempt to introduce an intelligent fleet management system was not successful. Their testing and startup costs exceeded NT 10 million, with more than several dozen test vendors. After discussion with company managers, the reasons for the earlier implementation failure were identified as follows: accumulated organizational cost considerations, resistance from employees to innovative changes, lack of professional know-how and experience in the project team, ongoing information technology innovation and evolution, and multiple patterns of customers and job complexity, leading to difficulties in system development.

4.2. Determining the Formal Decision Structure. Most of the decision-makers made their system implementation decisions based on their subjective views and various working 
TABLE 6: A formal decision structure for the case study.

\begin{tabular}{|c|c|c|}
\hline Aspects & Criteria & Descriptions \\
\hline \multirow{3}{*}{$\begin{array}{l}\text { Organization } \\
(A)\end{array}$} & Top executives support $(A 1)$ & $\begin{array}{l}\text { Executives' subjective preferences or understanding of the project, continued } \\
\text { participation, promises of funding and resources required, and removal of } \\
\text { obstacles to the project. }\end{array}$ \\
\hline & User recognition $(A 2)$ & $\begin{array}{l}\text { Whether employees have sufficient momentum to drive their participation in } \\
\text { the system. }\end{array}$ \\
\hline & Funding and budget $(A 3)$ & $\begin{array}{l}\text { The project budget for implementing software, hardware, and subsequent } \\
\text { maintenance requirements. }\end{array}$ \\
\hline \multirow{3}{*}{ Project base $(B)$} & Project team composition $(B 1)$ & $\begin{array}{l}\text { Organizations with outstanding staff from ministries can take up the } \\
\text { challenge and work together to resolve difficulties. }\end{array}$ \\
\hline & $\begin{array}{l}\text { Project management and } \\
\text { monitoring }(B 2)\end{array}$ & Project leaders and teams control project progress. \\
\hline & Education and training $(B 3)$ & Actual effectiveness of education and training. \\
\hline \multirow{3}{*}{$\begin{array}{l}\text { System } \\
\text { technology }(C)\end{array}$} & $\begin{array}{l}\text { Timely and correct information } \\
(C 1)\end{array}$ & Control over correct and timely input information. \\
\hline & $\begin{array}{l}\text { Degree of difficulty in software } \\
\text { and hardware maintenance }(C 2)\end{array}$ & $\begin{array}{l}\text { The degree of maintenance difficulty for the system and for hardware devices } \\
\text { in the future. }\end{array}$ \\
\hline & $\begin{array}{l}\text { Degree of completeness of } \\
\text { transmission equipment }(C 3)\end{array}$ & Transmission performance and scalability of equipment installed in a truck. \\
\hline \multirow{3}{*}{$\begin{array}{l}\text { External } \\
\text { environment } \\
\text { (D) }\end{array}$} & $\begin{array}{l}\text { Experience and ability of } \\
\text { consultants }(D 1)\end{array}$ & $\begin{array}{l}\text { Industrial familiarity, expressive capability, and communication skills of the } \\
\text { consultant. Level of professional competence of the consultant for each } \\
\text { module in the system. }\end{array}$ \\
\hline & $\begin{array}{l}\text { Coordination and } \\
\text { communication }(D 2)\end{array}$ & $\begin{array}{l}\text { Because the development of industry innovation is very rapid, when facing } \\
\text { competition, a further assessment of the competitive environment facing the } \\
\text { enterprise is required. }\end{array}$ \\
\hline & Customer acceptance (D3) & Willingness of customers to implement a system and conditions imposed. \\
\hline
\end{tabular}

rules. This approach was likely to lead to wrong decisions. To determine how to reduce the risk of failure, an objective and quantitative approach was required to help companies identify the key factors in successful system introduction. The $\mathrm{P}$ Transport Company was selected for this research as an empirical case to illustrate how to identify the key factors in introducing a GPS-based fleet management system. A survey was carried out to collect experts' perceptions, involving six managers from the $\mathrm{P}$ Transport Company who were involved in logistics and who had system software development experience.

35 aspects and 144 criteria were identified after a literature review. All these indicators were integrated according to similarities in definition and semantics, and five aspects and 18 criteria were selected for the prototype research architecture. To increase the possibility of success in implementing the GPS-based fleet management system, the Delphi method was used in this study to revise the prototype architecture into a formal decision structure as shown in Table 6. It was found that the consensus deviation index (CDI) in the Delphi method of each factor is lower than 0.1 after the third round, and four aspects and 12 criteria were thus considered in the final evaluation framework. Note that CDI is used to indicate the degree of the common consensus of consults. The greater the CDI is, the worse the common consensus will be. The questionnaire required by DEMATEL was designed, and ten qualified managers from the $\mathrm{P}$ Transport Company were invited to provide their opinions.

\subsection{Result Analysis}

4.3.1. Importance Analysis for Aspects. Based on the expert survey and the DEMATEL method, the initial direct influence matrix for aspects was calculated using (1), with the results shown in Table 7 . The normalized direct influence matrix was obtained using (2), with the results shown in Table 8. The total influence matrix was calculated using (3), with the results shown in Table 9. The prominence and relation of each aspect are shown in Table 10.

As shown in Table 11, a weighted supermatrix can be obtained by normalizing the total influence matrix. The limiting supermatrix derived by the weighted supermatrix was shown in Table 12.

The overall rankings for aspects are shown in Table 13 by arranging the sum of rankings of each aspect in ascending order. It is clear that "Organizations" is the most important aspect. According to the total influence matrix for aspects, a causal diagram depicted in Figure 4 shows that P Transport Company should energetically get down to performance improvement of "Organizations" to facilitate those of the other aspects. Also, it is reasonable for P Transport Company to undertake the development of appropriate strategies for improving "Organizations" because "Organizations" is categorized into a class of "cause." It is noted that the proposed causal diagram does not make use of prominences and relations. This is quite different from the traditional causal diagram. 
TABLE 7: The initial direct influence matrix for aspects.

\begin{tabular}{lcccc}
\hline Aspects & $A$ & $B$ & $C$ & $D$ \\
\hline$A$ & 0.0000 & 2.0000 & 2.4000 & 2.0000 \\
$B$ & 2.9000 & 0.0000 & 1.7000 & 1.0000 \\
$C$ & 2.8000 & 1.0000 & 0.0000 & 2.1000 \\
$D$ & 2.9000 & 1.7000 & 1.7000 & 0.0000 \\
\hline
\end{tabular}

TABLE 8: The normalized direct influence matrix for aspects.

\begin{tabular}{lcccc}
\hline Aspects & $A$ & $B$ & $C$ & $D$ \\
\hline$A$ & 0.0000 & 0.2326 & 0.2791 & 0.2326 \\
$B$ & 0.3372 & 0.0000 & 0.1977 & 0.1163 \\
$C$ & 0.3256 & 0.1163 & 0.0000 & 0.2442 \\
$D$ & 0.3372 & 0.1977 & 0.1977 & 0.0000 \\
\hline
\end{tabular}

TABLE 9: The total influence matrix for aspects.

\begin{tabular}{lccccc}
\hline Aspects & $A$ & $B$ & $C$ & $D$ & $d$ \\
\hline$A$ & 0.6278 & 0.5803 & 0.6905 & 0.6146 & 2.5132 \\
$B$ & 0.8166 & 0.3563 & 0.5933 & 0.4925 & 2.2587 \\
$C$ & 0.8389 & 0.4832 & 0.4492 & 0.6052 & 2.3765 \\
$D$ & 0.8761 & 0.5593 & 0.6366 & 0.4242 & 2.4963 \\
\hline$r$ & 3.1593 & 1.9791 & 2.3697 & 2.1365 & \\
\hline
\end{tabular}

TABle 10: Prominence and relation of each aspect.

\begin{tabular}{lcccc}
\hline Aspects & $d$ & $r$ & $d+r$ & $d-r$ \\
\hline$A$ & 2.5132 & 3.1593 & 5.6725 & -0.6462 \\
$B$ & 2.2587 & 1.9791 & 4.2378 & 0.2796 \\
$C$ & 2.3765 & 2.3697 & 4.7461 & 0.0068 \\
$D$ & 2.4963 & 2.1365 & 4.6328 & 0.3598 \\
\hline
\end{tabular}

TABLE 11: The weighted supermatrix for aspects.

\begin{tabular}{lcccc}
\hline Aspects & $A$ & $B$ & $C$ & $D$ \\
\hline$A$ & 0.1987 & 0.2932 & 0.2914 & 0.2877 \\
$B$ & 0.2585 & 0.1800 & 0.2504 & 0.2305 \\
$C$ & 0.2655 & 0.2442 & 0.1896 & 0.2832 \\
$D$ & 0.2773 & 0.2826 & 0.2686 & 0.1986 \\
\hline
\end{tabular}

TABLE 12: The limited supermatrix for aspects.

\begin{tabular}{lcccc}
\hline Aspects & $A$ & $B$ & $C$ & $D$ \\
\hline$A$ & 0.2662 & 0.2662 & 0.2662 & 0.2662 \\
$B$ & 0.2312 & 0.2312 & 0.2312 & 0.2312 \\
$C$ & 0.2464 & 0.2464 & 0.2464 & 0.2464 \\
$D$ & 0.2562 & 0.2562 & 0.2562 & 0.2562 \\
\hline
\end{tabular}

4.3.2. Importance Analysis for Criteria. Based on the expert survey and the use of the DEMATEL method, the initial direct influence matrix in Table 14 for criteria was calculated using (1). The normalized direct influence matrix in Table 15 was obtained through (2). The total influence matrix in Table 16 was calculated using (3). Table 17 summarizes the prominence and relation of each criterion; Table 18
TABLE 13: The overall ranking for aspects.

\begin{tabular}{lcccc}
\hline Aspects & DEMATEL & DANP & $\begin{array}{c}\text { Sum of } \\
\text { rankings }\end{array}$ & $\begin{array}{c}\text { Overall } \\
\text { rankings }\end{array}$ \\
\hline $\begin{array}{l}\text { Organizations }(A) \\
\text { Project base }(B)\end{array}$ & 1 & 1 & 2 & 1 \\
$\begin{array}{l}\text { System technology } \\
(C)\end{array}$ & 2 & 4 & 8 & 3 \\
$\begin{array}{l}\text { External } \\
\text { environment }(D)\end{array}$ & 3 & 2 & 5 & 2 \\
\hline
\end{tabular}

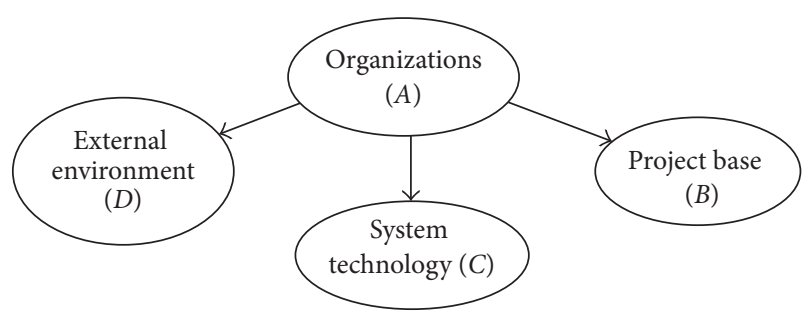

FIgURE 4: The causal diagram for aspects.

summarizes the cause/effect properties of twelve criteria considered.

As shown in Table 19, a weighted supermatrix can be obtained by normalizing the total influence matrix. The limiting supermatrix derived by the weighted supermatrix was shown in Table 20.

The overall rankings for criteria are shown in Table 21 by arranging the sum of rankings of each criterion in ascending order. According the overall ranking list, we take top executive support $(A 1)$, funding and budget $(A 3)$, experience and ability of consultant (D1), project team composition (B1), timely and correct information (C1), degree of completeness of transmission equipment $(C 3)$, and user recognition $(A 2)$ as key criteria.

4.3.3. Importance-Performance Analysis. To assess the criterion performances, ten managers $(S 1, S 2, \ldots, S 10)$ from the $\mathrm{P}$ Transport Company were invited as survey subjects. The relationship between rating and performance shown in Table 22 was also provided to subjects. The average values for the ten managers regarding performance on twelve criteria are shown in Table 23. After consulting ten experts, they all agreed to use 75 as a threshold value to distinguish criteria with acceptable $(\geq 75)$ or unacceptable $(<75)$ performance values from twelve criteria. Each criterion with its rank and performance value is depicted in Figure 5, which is used by IPA to examine which key factors should be concentrated.

From Figure 5, it can be seen that, in addition to top executive support $(A 1)$ and funding and budget (A3), five key criteria, such as timely and correct information $(C 1)$ and degree of completeness of transmission equipment (C3), fall into the upper right grid. P Transport Company should keep up the good performances of those key factors that fall into such a grid. Also, P Transport Company must effectively improve the performances of top executive support and 
TABLE 14: The initial direct influence matrix for criteria.

\begin{tabular}{lccccccccccccc}
\hline Criteria & $A 1$ & $A 2$ & $A 3$ & $B 1$ & $B 2$ & $B 3$ & $C 1$ & $C 2$ & $C 3$ & $D 1$ & $D 2$ \\
\hline$A 1$ & 0.0000 & 4.0000 & 4.0000 & 4.0000 & 2.4000 & 2.0000 & 2.8000 & 4.0000 & 2.0000 & 4.0000 & 3.0000 & 4.0000 \\
$A 2$ & 3.0000 & 0.0000 & 2.0000 & 1.8000 & 2.2000 & 2.0000 & 3.0000 & 0.0000 & 0.0000 & 0.0000 & 3.0000 & 2.0000 \\
$A 3$ & 3.9000 & 2.0000 & 0.0000 & 3.0000 & 1.9000 & 2.1000 & 2.4000 & 2.5000 & 2.5000 & 3.6000 & 2.0000 & 2.2000 \\
$B 1$ & 1.6000 & 2.7000 & 3.0000 & 0.0000 & 1.9000 & 3.0000 & 2.3000 & 2.0000 & 1.0000 & 1.7000 & 4.0000 & 2.9000 \\
$B 2$ & 1.0000 & 1.6000 & 1.0000 & 1.0000 & 0.0000 & 3.0000 & 2.4000 & 1.0000 & 2.0000 & 2.4000 & 2.6000 & 1.8000 \\
$B 3$ & 0.1000 & 1.5000 & 1.2000 & 0.2000 & 0.0000 & 0.0000 & 2.1000 & 0.0000 & 0.1000 & 0.4000 & 1.0000 & 1.4000 \\
$C 1$ & 2.0000 & 1.8000 & 2.0000 & 1.4000 & 1.6000 & 1.0000 & 0.0000 & 3.0000 & 0.0000 & 0.0000 & 1.0000 & 3.0000 \\
$C 2$ & 1.0000 & 1.0000 & 2.5000 & 1.4000 & 1.8000 & 1.9000 & 2.7000 & 0.0000 & 2.0000 & 2.5000 & 1.5000 & 1.4000 \\
$C 3$ & 2.5000 & 2.0000 & 2.9000 & 2.0000 & 1.9000 & 2.0000 & 2.6000 & 3.0000 & 0.0000 & 2.9000 & 1.0000 & 2.0000 \\
$D 1$ & 3.0000 & 3.0000 & 3.0000 & 0.8000 & 2.3000 & 3.0000 & 2.4000 & 0.0000 & 0.0000 & 0.0000 & 4.0000 & 3.0000 \\
$D 2$ & 2.9000 & 2.0000 & 0.0000 & 0.6000 & 1.6000 & 2.6000 & 2.1000 & 0.9000 & 0.0000 & 3.1000 & 0.0000 & 1.3000 \\
$D 3$ & 1.8000 & 1.3000 & 1.4000 & 0.2000 & 0.9000 & 0.3000 & 1.0000 & 0.0000 & 0.0000 & 0.0000 & 1.8000 & 0.0000 \\
\hline
\end{tabular}

TABLE 15: The normalized direct influence matrix for criteria.

\begin{tabular}{lccccccccccccc}
\hline Criteria & $A 1$ & $A 2$ & $A 3$ & $B 1$ & $B 2$ & $B 3$ & $C 1$ & $C 2$ & $C 3$ & $D 1$ & $D 2$ & $D 3$ \\
\hline$A 1$ & 0.0000 & 0.1105 & 0.1105 & 0.1105 & 0.0663 & 0.0552 & 0.0773 & 0.1105 & 0.0552 & 0.1105 & 0.0829 & 0.1105 \\
$A 2$ & 0.0829 & 0.0000 & 0.0552 & 0.0497 & 0.0608 & 0.0552 & 0.0829 & 0.0000 & 0.0000 & 0.0000 & 0.0829 & 0.0552 \\
$A 3$ & 0.1077 & 0.0552 & 0.0000 & 0.0829 & 0.0525 & 0.0580 & 0.0663 & 0.0691 & 0.0691 & 0.0994 & 0.0552 & 0.0608 \\
$B 1$ & 0.0442 & 0.0746 & 0.0829 & 0.0000 & 0.0525 & 0.0829 & 0.0635 & 0.0552 & 0.0276 & 0.0470 & 0.1105 & 0.0801 \\
B2 & 0.0276 & 0.0442 & 0.0276 & 0.0276 & 0.0000 & 0.0829 & 0.0663 & 0.0276 & 0.0552 & 0.0663 & 0.0718 & 0.0497 \\
$B 3$ & 0.0028 & 0.0414 & 0.0331 & 0.0055 & 0.0000 & 0.0000 & 0.0580 & 0.0000 & 0.0028 & 0.0110 & 0.0276 & 0.0387 \\
$C 1$ & 0.0552 & 0.0497 & 0.0552 & 0.0387 & 0.0442 & 0.0276 & 0.0000 & 0.0829 & 0.0000 & 0.0000 & 0.0276 & 0.0829 \\
$C 2$ & 0.0276 & 0.0276 & 0.0691 & 0.0387 & 0.0497 & 0.0525 & 0.0746 & 0.0000 & 0.0552 & 0.0691 & 0.0414 & 0.0387 \\
$C 3$ & 0.0691 & 0.0552 & 0.0801 & 0.0552 & 0.0525 & 0.0552 & 0.0718 & 0.0829 & 0.0000 & 0.0801 & 0.0276 & 0.0552 \\
D1 & 0.0829 & 0.0829 & 0.0829 & 0.0221 & 0.0635 & 0.0829 & 0.0663 & 0.0000 & 0.0000 & 0.0000 & 0.1105 & 0.0829 \\
D2 & 0.0801 & 0.0552 & 0.0000 & 0.0166 & 0.0442 & 0.0718 & 0.0580 & 0.0249 & 0.0000 & 0.0856 & 0.0000 & 0.0359 \\
$D 3$ & 0.0497 & 0.0359 & 0.0387 & 0.0055 & 0.0249 & 0.0083 & 0.0276 & 0.0000 & 0.0000 & 0.0000 & 0.0497 & 0.0000 \\
\hline
\end{tabular}

TABLE 16: The total influence matrix for criteria.

\begin{tabular}{lccccccccccccccc}
\hline Criteria & $A 1$ & $A 2$ & $A 3$ & $B 1$ & $B 2$ & $B 3$ & $C 1$ & $C 2$ & $C 3$ & $D 1$ & $D 2$ & $D 3$ \\
\hline$A 1$ & 0.1250 & 0.2233 & 0.2211 & 0.1894 & 0.1618 & 0.1718 & 0.2066 & 0.1854 & 0.1023 & 0.2070 & 0.2120 & 0.2347 & 2.2404 \\
$A 2$ & 0.1424 & 0.0664 & 0.1129 & 0.0954 & 0.1090 & 0.1150 & 0.1484 & 0.0500 & 0.0274 & 0.0582 & 0.1475 & 0.1249 & 1.1975 \\
$A 3$ & 0.1991 & 0.1544 & 0.1007 & 0.1508 & 0.1311 & 0.1526 & 0.1722 & 0.1371 & 0.1064 & 0.1808 & 0.1621 & 0.1682 & 1.8155 \\
$B 1$ & 0.1294 & 0.1542 & 0.1563 & 0.0593 & 0.1173 & 0.1606 & 0.1537 & 0.1094 & 0.0602 & 0.1181 & 0.1938 & 0.1663 & 1.5786 \\
$B 2$ & 0.0915 & 0.1064 & 0.0878 & 0.0699 & 0.0504 & 0.1407 & 0.1334 & 0.0697 & 0.0753 & 0.1158 & 0.1356 & 0.1170 & 1.1936 \\
$B 3$ & 0.0316 & 0.0647 & 0.0553 & 0.0240 & 0.0212 & 0.0230 & 0.0828 & 0.0183 & 0.0112 & 0.0296 & 0.0533 & 0.0655 & 0.4804 \\
$C 1$ & 0.1085 & 0.1029 & 0.1082 & 0.0795 & 0.0883 & 0.0807 & 0.0629 & 0.1188 & 0.0273 & 0.0512 & 0.0885 & 0.1398 & 1.0567 \\
$C 2$ & 0.0962 & 0.0947 & 0.1311 & 0.0855 & 0.1019 & 0.1164 & 0.1447 & 0.0487 & 0.0806 & 0.1242 & 0.1120 & 0.1116 & 1.2477 \\
$C 3$ & 0.1521 & 0.1393 & 0.1621 & 0.1165 & 0.1205 & 0.1368 & 0.1635 & 0.1403 & 0.0376 & 0.1511 & 0.1215 & 0.1482 & 1.5895 \\
$D 1$ & 0.1614 & 0.1602 & 0.1518 & 0.0802 & 0.1243 & 0.1561 & 0.1513 & 0.0561 & 0.0320 & 0.0695 & 0.1910 & 0.1665 & 1.5002 \\
$D 2$ & 0.1319 & 0.1132 & 0.0593 & 0.0575 & 0.0890 & 0.1249 & 0.1196 & 0.0625 & 0.0217 & 0.1277 & 0.0654 & 0.1007 & 1.0734 \\
$D 3$ & 0.0816 & 0.0679 & 0.0671 & 0.0315 & 0.0508 & 0.0399 & 0.0624 & 0.0252 & 0.0143 & 0.0309 & 0.0824 & 0.0359 & 0.5899 \\
\hline$r$ & 1.4507 & 1.4476 & 1.4136 & 1.0395 & 1.1656 & 1.4185 & 1.6015 & 1.0217 & 0.5964 & 1.2641 & 1.5651 & 1.5790 \\
\hline
\end{tabular}

funding and budget that fall into the upper left grid. Of course, $A 1$ and $A 3$ would pose a serious threat to $\mathrm{P}$ Transport Company if they are ignored. Also, resources committed to those criteria that fall into lower right grid would be better employed elsewhere, and it is not necessary to focus additional effort on $C 2$.
According to the total influence matrix in Table 13, a causal diagram depicted in Figure 4 shows that P Transport Company should energetically get down to performance improvements of top executive support $(A 1)$ and funding and budget $(A 3)$ for introducing GPS-based fleet management systems to facilitate those of the other key factors. Also, 


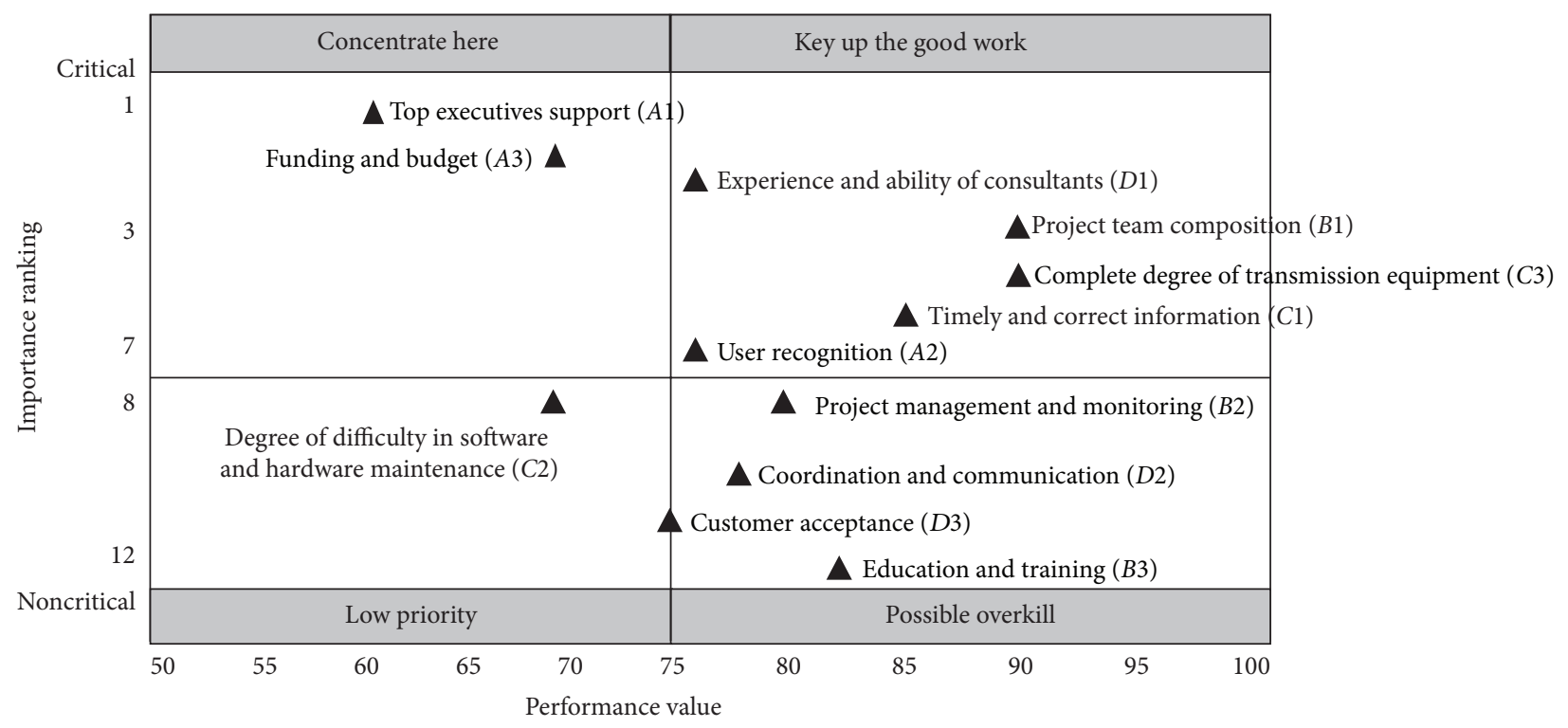

FIGURE 5: IPA for evaluation criteria.

TABLE 17: Prominence and relation of each criterion.

\begin{tabular}{lcccc}
\hline Criteria & $d$ & $r$ & $d+r$ & $d-r$ \\
\hline$A 1$ & 2.2404 & 1.4507 & 3.6911 & 0.7897 \\
$A 2$ & 1.1975 & 1.4476 & 2.6451 & -0.2500 \\
$A 3$ & 1.8155 & 1.4136 & 3.2291 & 0.4018 \\
$B 1$ & 1.5786 & 1.0395 & 2.6181 & 0.5390 \\
$B 2$ & 1.1936 & 1.1656 & 2.3592 & 0.0280 \\
$B 3$ & 0.4804 & 1.4185 & 1.8990 & -0.9381 \\
$C 1$ & 1.0567 & 1.6015 & 2.6582 & -0.5448 \\
$C 2$ & 1.2477 & 1.0217 & 2.2694 & 0.2260 \\
$C 3$ & 1.5895 & 0.5964 & 2.1860 & 0.9931 \\
$D 1$ & 1.5002 & 1.2641 & 2.7643 & 0.2362 \\
$D 2$ & 1.0734 & 1.5651 & 2.6386 & -0.4917 \\
$D 3$ & 0.5899 & 1.5790 & 2.1689 & -0.9891 \\
\hline
\end{tabular}

the selection of $A 1$ and $A 3$ to be the start is very appropriate because they are categorized into a class of "cause." To improve $A 1$ effectively, executives of $\mathrm{P}$ Transport Company should promise that they must continue participation, provide funding and resources required, and remove obstacles actively to the project for the introduction of GPS-based fleet management systems. As for performance improvement of A3, P Transport Company should provide adequate budget for implementing the software, hardware, and subsequent maintenance requirements. In Figure 6 , it can be seen that $A 1$ and $A 3$ influenced each other. This means that adequate annual funding and budget planning are necessary in the long term so as to enhance the faith of top executives for successfully introducing the information systems to $\mathrm{P}$ Transport Company. As in the previous subsection, the proposed causal diagram is a kind of NRM and does not make use of prominences and relations.
Since the improvement of $A 1$ with the worst rating is urgent for $\mathrm{P}$ Transport Company, in addition to $A 3$, it is interesting to explore whether other factors can have certain influence on $A 1$. The total influence matrix shows that $A 3$ has the greatest impact on $A 1$ and key criteria $D 1, C 3$, and $A 2$ have the second, the third, and the forth greatest impacts, respectively. It is reasonable to speculate that enhancement of intention of using the systems for employees and collaboration with consultants with high specialty can be helpful to enhance the support of executives. In Figure 6, the former and the latter impacts on $A 1$ coming from $A 2$ and $D 1$ are indicated as dashed lines. The abovementioned strategies for $A 1$ and $A 3$ can concretely implement the improvement of "Organizations." It is suggested that leverage of the total influence matrix and the causal diagram could help us develop strategies of improvement in key factors, especially for those falling into the upper left grid in IPA. Such an analysis has its potentiality of being widely applied to other problem domains.

\section{Conclusions}

Intelligent transportation systems have been in operation for many years, and commercial vehicle operation issues have become important ITS trends in many developed countries. GPS-based fleet management systems are very important to the logistics industry, especially in transport companies. These systems can monitor and track commodity distribution, thus saving energy. Moreover, they also improve scheduling, operating efficiency, and effectiveness. Because fleet management systems are very important, the successful introduction of these systems has become a key issue.

The purpose of this research was to identify the key factors for introducing GPS-based fleet management systems to transport companies. DEMATEL and ANP were combined 
TABlE 18: Cause/effect properties of criteria.

\begin{tabular}{ll}
\hline Cause/effect & Criteria \\
\hline Cause & $\begin{array}{l}\text { Top executives support }(A 1), \text { funding and budget }(A 3) \text {, project team composition }(B 1) \text {, project management and } \\
\text { monitoring }(B 2) \text {, degree of difficulty in software and hardware maintenance }(C 2), \text { complete degree of transmission } \\
\text { equipment }(C 3) \text {, and experience and ability of consultants }(D 1)\end{array}$ \\
\hline Effect & $\begin{array}{l}\text { User recognition }(A 2), \text { education and training }(B 3) \text {, timely and correct information }(C 1) \text {, coordination and } \\
\text { communication }(D 2) \text {, and customer acceptance }(D 3)\end{array}$ \\
\hline
\end{tabular}

TABle 19: The weighted supermatrix for criteria.

\begin{tabular}{cccccccccccccc}
\hline & $A 1$ & $A 2$ & $A 3$ & $B 1$ & $B 2$ & $B 3$ & $C 1$ & $C 2$ & $C 3$ & $D 1$ & $D 2$ & $D 3$ \\
\hline$A 1$ & 0.0862 & 0.1542 & 0.1564 & 0.1822 & 0.1388 & 0.1211 & 0.1290 & 0.1815 & 0.1715 & 0.1637 & 0.1355 & 0.1486 \\
$A 2$ & 0.0982 & 0.0459 & 0.0799 & 0.0917 & 0.0935 & 0.0810 & 0.0927 & 0.0490 & 0.0459 & 0.0461 & 0.0943 & 0.0791 \\
$A 3$ & 0.1372 & 0.1066 & 0.0712 & 0.1451 & 0.1125 & 0.1076 & 0.1075 & 0.1342 & 0.1784 & 0.1430 & 0.1036 & 0.1065 \\
$B 1$ & 0.0892 & 0.1065 & 0.1105 & 0.0570 & 0.1007 & 0.1132 & 0.0960 & 0.1071 & 0.1009 & 0.0934 & 0.1238 & 0.1053 \\
$B 2$ & 0.0631 & 0.0735 & 0.0621 & 0.0673 & 0.0432 & 0.0992 & 0.0833 & 0.0682 & 0.1263 & 0.0916 & 0.0866 & 0.0741 \\
$B 3$ & 0.0218 & 0.0447 & 0.0391 & 0.0230 & 0.0182 & 0.0162 & 0.0517 & 0.0179 & 0.0188 & 0.0234 & 0.0341 & 0.0415 \\
$C 1$ & 0.0748 & 0.0711 & 0.0765 & 0.0765 & 0.0757 & 0.0569 & 0.0393 & 0.1163 & 0.0458 & 0.0405 & 0.0566 & 0.0885 \\
$C 2$ & 0.0663 & 0.0654 & 0.0927 & 0.0822 & 0.0874 & 0.0821 & 0.0904 & 0.0477 & 0.1352 & 0.0983 & 0.0716 & 0.0707 \\
$C 3$ & 0.1048 & 0.0963 & 0.1147 & 0.1121 & 0.1034 & 0.0965 & 0.1021 & 0.1374 & 0.0630 & 0.1195 & 0.0776 & 0.0938 \\
$D 1$ & 0.1112 & 0.1106 & 0.1074 & 0.0771 & 0.1066 & 0.1101 & 0.0945 & 0.0549 & 0.0537 & 0.0549 & 0.1220 & 0.1054 \\
$D 2$ & 0.0909 & 0.0782 & 0.0420 & 0.0554 & 0.0764 & 0.0880 & 0.0747 & 0.0612 & 0.0364 & 0.1011 & 0.0418 & 0.0638 \\
$D 3$ & 0.0562 & 0.0469 & 0.0474 & 0.0303 & 0.0436 & 0.0281 & 0.0390 & 0.0247 & 0.0240 & 0.0245 & 0.0527 & 0.0227 \\
\hline
\end{tabular}

TABLE 20: The limited supermatrix for criteria.

\begin{tabular}{lccccccccccccc}
\hline & $A 1$ & $A 2$ & $A 3$ & $B 1$ & $B 2$ & $B 3$ & $C 1$ & $C 2$ & $C 3$ & $D 1$ & $D 2$ & $D 3$ \\
\hline$A 1$ & 0.1469 & 0.1469 & 0.1469 & 0.1469 & 0.1469 & 0.1469 & 0.1469 & 0.1469 & 0.1469 & 0.1469 & 0.1469 & 0.1469 \\
$A 2$ & 0.0749 & 0.0749 & 0.0749 & 0.0749 & 0.0749 & 0.0749 & 0.0749 & 0.0749 & 0.0749 & 0.0749 & 0.0749 & 0.0749 \\
$A 3$ & 0.1238 & 0.1238 & 0.1238 & 0.1238 & 0.1238 & 0.1238 & 0.1238 & 0.1238 & 0.1238 & 0.1238 & 0.1238 & 0.1238 \\
$B 1$ & 0.0980 & 0.0980 & 0.0980 & 0.0980 & 0.0980 & 0.0980 & 0.0980 & 0.0980 & 0.0980 & 0.0980 & 0.0980 & 0.0980 \\
$B 2$ & 0.0766 & 0.0766 & 0.0766 & 0.0766 & 0.0766 & 0.0766 & 0.0766 & 0.0766 & 0.0766 & 0.0766 & 0.0766 & 0.0766 \\
$B 3$ & 0.0285 & 0.0285 & 0.0285 & 0.0285 & 0.0285 & 0.0285 & 0.0285 & 0.0285 & 0.0285 & 0.0285 & 0.0285 & 0.0285 \\
$C 1$ & 0.0687 & 0.0687 & 0.0687 & 0.0687 & 0.0687 & 0.0687 & 0.0687 & 0.0687 & 0.0687 & 0.0687 & 0.0687 & 0.0687 \\
$C 2$ & 0.0838 & 0.0838 & 0.0838 & 0.0838 & 0.0838 & 0.0838 & 0.0838 & 0.0838 & 0.0838 & 0.0838 & 0.0838 & 0.0838 \\
$C 3$ & 0.1031 & 0.1031 & 0.1031 & 0.1031 & 0.1031 & 0.1031 & 0.1031 & 0.1031 & 0.1031 & 0.1031 & 0.1031 & 0.1031 \\
$D 1$ & 0.0906 & 0.0906 & 0.0906 & 0.0906 & 0.0906 & 0.0906 & 0.0906 & 0.0906 & 0.0906 & 0.0906 & 0.0906 & 0.0906 \\
$D 2$ & 0.0666 & 0.0666 & 0.0666 & 0.0666 & 0.0666 & 0.0666 & 0.0666 & 0.0666 & 0.0666 & 0.0666 & 0.0666 & 0.0666 \\
$D 3$ & 0.0386 & 0.0386 & 0.0386 & 0.0386 & 0.0386 & 0.0386 & 0.0386 & 0.0386 & 0.0386 & 0.0386 & 0.0386 & 0.0386 \\
\hline
\end{tabular}

TABLE 21: The overall ranking for criteria.

\begin{tabular}{|c|c|c|c|c|}
\hline Criteria & DEMATEL & DANP & Sum of rankings & Overall rankings \\
\hline Top executives support $(A 1)$ & 1 & 1 & 2 & 1 \\
\hline User recognition $(A 2)$ & 5 & 8 & 13 & 5 \\
\hline Funding and budget $(A 3)$ & 2 & 2 & 4 & 2 \\
\hline Project team composition $(B 1)$ & 7 & 4 & 11 & 4 \\
\hline Project management and monitoring $(B 2)$ & 8 & 7 & 15 & 8 \\
\hline Education and training $(B 3)$ & 12 & 12 & 24 & 12 \\
\hline Timely and correct information $(C 1)$ & 4 & 9 & 13 & 5 \\
\hline Degree of difficulty in software and hardware maintenance $(C 2)$ & 9 & 6 & 15 & 8 \\
\hline Degree of completeness of transmission equipment $(C 3)$ & 10 & 3 & 13 & 5 \\
\hline Experience and ability of consultants $(D 1)$ & 3 & 5 & 8 & 3 \\
\hline Coordination and communication (D2) & 6 & 10 & 16 & 10 \\
\hline Customer acceptance (D3) & 11 & 11 & 22 & 11 \\
\hline
\end{tabular}


TABLE 22: Relationship between rating and performance.

\begin{tabular}{lccccc}
\hline Rating & 0 & 25 & 50 & 75 & 100 \\
\hline Performance & Very dissatisfied & Dissatisfied & Ordinary & Satisfied & Very satisfied \\
\hline
\end{tabular}

TABLE 23: Performance assessment of twelve criteria.

\begin{tabular}{|c|c|c|c|c|c|c|c|c|c|c|c|}
\hline \multirow{2}{*}{ Criteria } & \multicolumn{10}{|c|}{ Subjects } & \multirow{2}{*}{ Average } \\
\hline & $S 1$ & $S 2$ & $S 3$ & S4 & S5 & S6 & $S 7$ & $S 8$ & $S 9$ & $S 10$ & \\
\hline Top executives support $(A 1)$ & 60 & 65 & 65 & 65 & 60 & 60 & 55 & 65 & 65 & 50 & 61 \\
\hline User recognition $(A 2)$ & 85 & 80 & 70 & 75 & 75 & 65 & 80 & 75 & 80 & 70 & 76 \\
\hline Funding and budget $(A 3)$ & 75 & 75 & 60 & 75 & 80 & 75 & 60 & 60 & 65 & 70 & 70 \\
\hline Project team composition $(B 1)$ & 90 & 95 & 85 & 85 & 90 & 90 & 90 & 85 & 95 & 95 & 90 \\
\hline Project management and monitoring $(B 2)$ & 80 & 75 & 80 & 75 & 85 & 75 & 80 & 90 & 90 & 80 & 81 \\
\hline Education and training $(B 3)$ & 80 & 80 & 80 & 90 & 85 & 75 & 80 & 80 & 90 & 90 & 83 \\
\hline Timely and correct information $(C 1)$ & 85 & 80 & 90 & 90 & 85 & 90 & 80 & 85 & 80 & 80 & 85 \\
\hline $\begin{array}{l}\text { Degree of difficulty software and } \\
\text { hardware maintenance }(C 2)\end{array}$ & 70 & 75 & 65 & 75 & 80 & 75 & 60 & 60 & 70 & 70 & 70 \\
\hline $\begin{array}{l}\text { Complete degree of transmission } \\
\text { equipment }(C 3)\end{array}$ & 90 & 95 & 85 & 90 & 90 & 90 & 90 & 85 & 95 & 85 & 90 \\
\hline Experience and ability of consultant $(D 1)$ & 75 & 75 & 75 & 80 & 80 & 80 & 75 & 70 & 70 & 75 & 76 \\
\hline Coordination and communication (D2) & 70 & 75 & 80 & 85 & 80 & 75 & 70 & 80 & 80 & 70 & 77 \\
\hline Customer acceptance (D3) & 80 & 75 & 70 & 75 & 75 & 70 & 80 & 75 & 80 & 70 & 75 \\
\hline
\end{tabular}

to determine the key indicators, identify the most important one, and discover how it affects others. Top executive support was determined to be the most important criterion in this study; other key factors selected were funding and budget, experience and ability of consultants, project team composition, user recognition, timely and correct information, and degree of completeness of transmission equipment. These seven key factors are discussed below.

Large organizations cannot avoid bureaucratic cultures and egos. The introduction of new technologies and systems will replace existing modes of operation, often leading to resistance from conservative older employees and executives who are unwilling to change. The functioning of the organization from the financial, technical, and training units to the business units determines the success or failure of a system introduction. Only executives can formulate topdown requirements and determine that system implementation becomes a clear policy objective before they can drive innovation across the enterprise.

In the case of enterprises with limited resources, implementing a new system requires large amounts of funding, time, and human resources which are not necessarily proportional to the rate of return that can be obtained. This reality makes executives and shareholders conservative. Before implementing a system, a large budget must be set aside, which will affect the current year net income and, after implementation, system maintenance costs will continue as long-term operating costs. Implementing new systems is closely related to funding, and only executives can set aside budgets, whereas the company has the resources for system development and implementation.
Implementing new technology and systems is not original business expertise and relies heavily on the technology and experience of manufacturers to avoid costly mistakes. Large organizations are looking for manufacturers with welloiled operations and similar size to ensure system operation and maintenance. Therefore, the experience and ability of consultants are important to enterprises. The composition of the project team has a major impact on successful system implementation. Members must have expertise in various sectors to fully express the operating system requirements of different departments, thus facilitating interagency communication and coordination and helping system specification and development. Innovation is not only driven by executives, but requires the cooperation of all. All users must accept change, modify habits, and adopt new operating procedures to enhance operational effectiveness. A new GPS system has been developed which aims to achieve map database integration, including real-time control data related to vehicle dynamics and driving, speed, braking, emergency deceleration, arrival time, temperature recording, and other important management information. Timely and correct system output is the basic requirement for the transport company.

The transmission equipment implemented for this GPS system features a link through the car's transmission to transmit relevant information back to the company. Based on the current distinction between $2 \mathrm{G}$ and $3 \mathrm{G}$, a $3 \mathrm{G}$ system with integrated touch screen and built-in CPU and memory was chosen for this project. It was able to collect data on a device and send it through the device's built-in program module without preprocessing. The information was then transmitted 


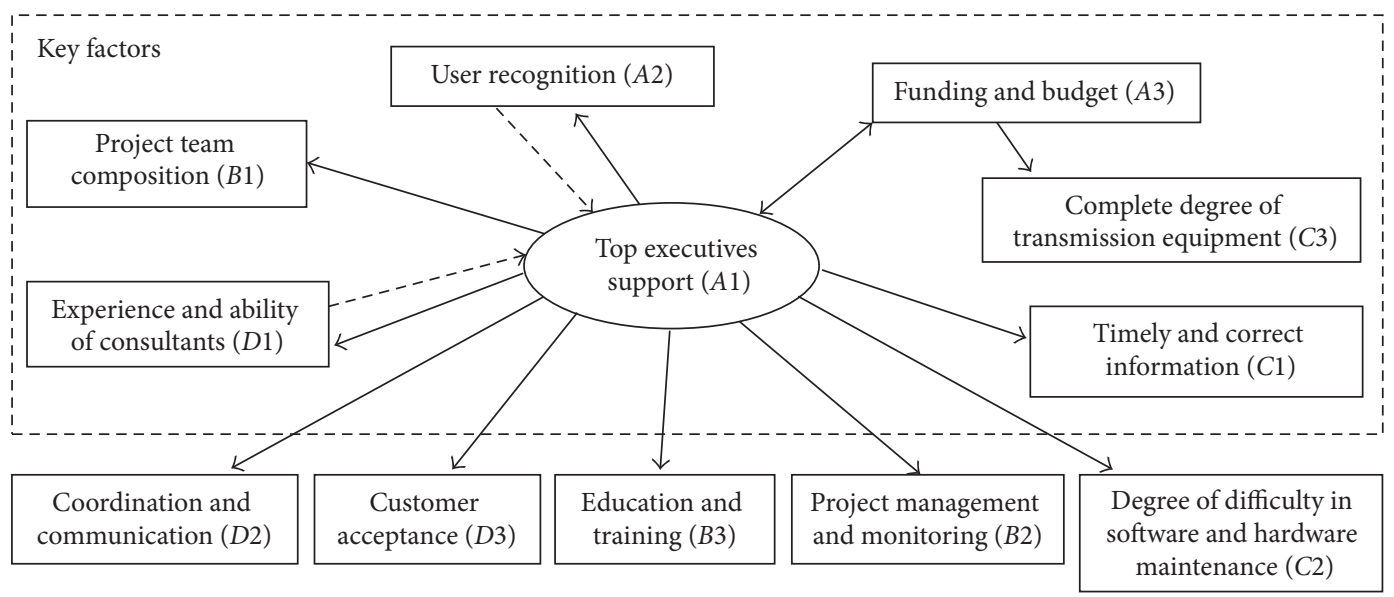

FIGURE 6: The causal diagram for evaluation criteria.

over a 3G link to the background, avoiding too heavy burden on this background, to enhance the availability of accurate real-time information.

For the transport industry, traffic accidents are the main causes of violations caused by domestic carriers. Many casualties of trucks occurred in the past and have tended to place less emphasis on the implementation of GPS-based fleet management systems. Actually, violations can be reduced with successful implementation of a system to avoid social harm. Abnormal driving behavior will become apparent through the fleet management system (speed, travel time, driving illegal routes, etc.), and a temperature control feature will be available in real time to prevent excessive heating or cooling during delivery of goods, ensuring food safety. These research results can be used by the logistics industry to implement a GPS-based fleet management system. As for factory management, logistics operators can also be used as an important reference for future systems before importing data. The system will also provide opportunities to learn from others in the transport sector, thereby enhancing the overall quality of transportation services.

\section{Conflict of Interests}

The authors declare that there is no conflict of interests regarding the publication of this paper.

\section{Acknowledgments}

The authors would like to thank the anonymous referees for their valuable comments. This research is partially supported by the National Science Council of Taiwan under Grant no. NSC 102-2410-H-033-039-MY2.

\section{References}

[1] T. G. Crainic and G. Laporte, Fleet Management and Logistics, Kluwer Academic Publishers, Boston, Mass, USA, 1998.

[2] J. Mele, "Fleet management systems: the future is here," Fleet Owner, vol. 100, no. 8, p. 88, 2005.
[3] T. McLoad, Fleet Management Systems: The Future is Here, Fleet Owner, 2005.

[4] R. van der Heijden and V. Marchau, "Innovating road traffic management by ITS: a future perspective," International Journal of Technology, Policy and Management, vol. 2, no. 1, pp. 20-39, 2002.

[5] C. G. Sørensen and D. D. Bochtis, "Conceptual model of fleet management in agriculture," Biosystems Engineering, vol. 105, no. 1, pp. 41-50, 2010.

[6] G. Mintsis, S. Basbas, P. Papaioannou, C. Taxiltaris, and I. N. Tziavos, "Applications of GPS technology in the land transportation system," European Journal of Operational Research, vol. 152, no. 2, pp. 399-409, 2004.

[7] N. Nandan, "Online grid-based dynamic arrival time prediction using GPS locations," International Journal of Machine Learning and Computing, vol. 3, no. 6, pp. 516-519, 2013.

[8] J. Lü and G. Chen, "A time-varying complex dynamical network model and its controlled synchronization criteria," IEEE Transactions on Automatic Control, vol. 50, no. 6, pp. 841-846, 2005.

[9] J. Lü, X. Yu, G. Chen, and D. Cheng, "Characterizing the synchronizability of small-world dynamical networks," IEEE Transactions on Circuits and Systems. I. Regular Papers, vol. 51, no. 4, pp. 787-796, 2004.

[10] S. Tan and J. Lü, "Characterizing the effect of population heterogeneity on evolutionary dynamics on complex networks," Scientific Reports, vol. 4, article 5034, 2014.

[11] Y. Chen, J. Lü, X. Yu, and Z. Lin, "Consensus of discrete-time second-order multiagent systems based on infinite products of general stochastic matrices," SIAM Journal on Control and Optimization, vol. 51, no. 4, pp. 3274-3301, 2013.

[12] S.-H. Chung, A. H. I. Lee, and W. L. Pearn, "Analytic network process (ANP) approach for product mix planning in semiconductor fabricator," International Journal of Production Economics, vol. 96, no. 1, pp. 15-36, 2005.

[13] Y. C. Hu and Y. L. Liao, "Utilizing analytic hierarchy process to analyze consumers' purchase evaluation factors of smartphones," World Academy of Science, Engineering and Technology, vol. 78, pp. 1047-1052, 2013.

[14] Y. C. Hu, "Analytic network process for pattern classification problems using genetic algorithms," Information Sciences, vol. 180, no. 13, pp. 2528-2539, 2010. 
[15] Y. C. Hu, J. H. Wang, and R. Y. Wang, "Evaluating the performance of Taiwan Homestay using analytic network Process," Mathematical Problems in Engineering, vol. 2012, Article ID 827193, 24 pages, 2012.

[16] Y. C. Hu, J. H. Wang, and L. P. Hung, "Evaluating the e-service quality of microblogging," in Proceedings of the International Symposium on the Analytic Hierarchy Process, Naples, Italy, 2011.

[17] C.-L. Lin, M.-S. Hsieh, and G.-H. Tzeng, "Evaluating Vehicle Telematics System by using a novel MCDM techniques with dependence and feedback," Expert Systems with Applications, vol. 37, no. 10, pp. 6723-6736, 2010.

[18] W.-W. Wu, "Choosing knowledge management strategies by using a combined ANP and DEMATEL approach," Expert Systems with Applications, vol. 35, no. 3, pp. 828-835, 2008.

[19] J. L. Yang and G.-H. Tzeng, "An integrated MCDM technique combined with DEMATEL for a novel cluster-weighted with ANP method," Expert Systems with Applications, vol. 38, no. 3, pp. 1417-1424, 2011.

[20] G.-H. Tzeng and J.-J. Huang, Multiple Attribute Decision Making: Methods and Applications, CRC Press, Boca Raton, Fla, USA, 2011.

[21] C. Y. Hern, "Schedule planning for the development of intelligent transportation systems (ITS) in Taiwan area," Transportation Planning Journal, vol. 29, no. 1, pp. 109-142, 2000.

[22] Y. J. Chiu and G. H. Tzeng, "Evaluating intelligent transportation security systems using MCDM," in Proceedings of the 30th International Conference on Computers and Industrial Engineering, pp. 131-136, Tinos Island, Greece, June-July 2002.

[23] B. K. S. Cheung, K. L. Choy, C. L. Li, W. Shi, and J. Tang, "Dynamic routing model and solution methods for fleet management with mobile technologies," International Journal of Production Economics, vol. 113, no. 2, pp. 694-705, 2008.

[24] E. E. Adam and R. J. Ebert, Production and Operations Management: Concepts, Models and Behaviour, Prentice Hall, New York, NY, USA, 5th edition, 1991.

[25] Definition of Global Positioning Systems. The American Heritage Dictionary, Houghton Mifflin, Boston, Mass, USA, 4th edition, 2000.

[26] C. R. Drane and C. Rizos, Positioning Systems in Intelligent Transportation Systems, Artech House Publishers, 1998.

[27] Y. Zhao, Vehicle Location and Navigation Systems, Artech House Publishers, Norwood, Mass, USA, 1997.

[28] A. Theiss, D. C. Yen, and C.-Y. Ku, "Global positioning systems: an analysis of applications, current development and future implementations," Computer Standards and Interfaces, vol. 27, no. 2, pp. 89-100, 2005.

[29] J. Karp, "GPS in interstate trucking in Australia: intelligence, surveillance- or compliance tool?" IEEE Technology and Society Magazine, vol. 33, no. 2, pp. 47-52, 2014.

[30] H. Auernhammer, "Precision farming-the environmental challenge," Computers and Electronics in Agriculture, vol. 30, no. 1-3, pp. 31-43, 2001.

[31] Y. P. O. Yang, H. M. Shieh, J. D. Leu, and G. H. Tzeng, "A novel hybrid MCDM model combined with DEMATEL and ANP with applications," International Journal of Operations Research, vol. 5, no. 3, pp. 160-168, 2008.

[32] Y.-C. Hu and J.-F. Tsai, "Backpropagation multi-layer perceptron for incomplete pairwise comparison matrices in analytic hierarchy process," Applied Mathematics and Computation, vol. 180, no. 1, pp. 53-62, 2006.
[33] Z. Xu and C. Wei, "Consistency improving method in the analytic hierarchy process," European Journal of Operational Research, vol. 116, no. 2, pp. 443-449, 1999.

[34] J. A. Martilla and J. C. James, "Importance-performance analysis," Journal of Marketing, vol. 41, no. 1, pp. 77-79, 1977.

[35] C. C. Chen, K. C. Chen, and J. R. Chen, "The study of key success factors of ERP implementation in the small business," Journal of Chinese Economic Research, vol. 10, no. 2, pp. 31-42, 2012.

[36] H. Y. Chiou, Analyses of the critical success factors on the implementation of ERP system: a study in the point of ERP project manager [Master thesis], Shih Chien University, Taipei, Taiwan, 2010.

[37] J. H. Huang, Apply analytic network process to explore the critical success factors for enterprises implementing ERP systems [M.S. thesis], National Kaohsiung University of Applied Sciences, Kaohsiung, Taiwan, 2012.

[38] S. M. Huang, S. I. Chang, and K. H. Su, "Critical success factors for implementing BS7799 information security management system-based on petrochemical industry," Journal of Information Management, vol. 13, no. 2, pp. 171-192, 2006.

[39] H. C. Lee, Applying grey analytic hierarchy process to analyze the critical success factors of ERP [M.S. thesis], Huafan University, Taipei, Taiwan, 2007.

[40] H. C. Lin, Exploration of key successful factors of ERP implementation for small and medium firms [M.S. thesis], National Cheng Kung University, Tainan, Taiwan, 2010.

[41] C. M. Liu, Critical success factors research of information system of military organization implementation: example of army training and supply systems [M.S. thesis], Southern Taiwan University of Science and Technology, Tainan, Taiwan, 2012.

[42] J. C. Pai, G. G. Lee, W. G. Tseng, and Y. L. Chang, "Organizational, technological and environmental factors affecting the implementation of ERP systems: multiple-case study in Taiwan," Journal of Electronic Commerce Studies, vol. 5, no. 2, pp. 175-195, 2007.

[43] I. H. Sheu, Influence enterprise resources plan system CSF (Critical Success Factor) implement success-from consultant discussion viewpoint [M.S. thesis], National Kaohsiung First University, Kaohsiung, Taiwan, 2006. 


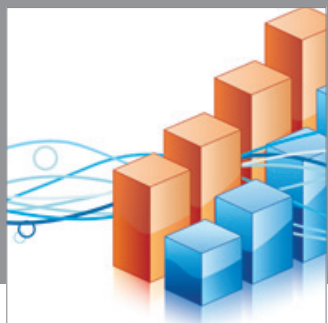

Advances in

Operations Research

mansans

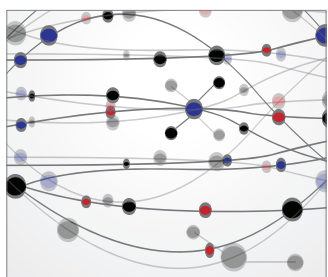

The Scientific World Journal
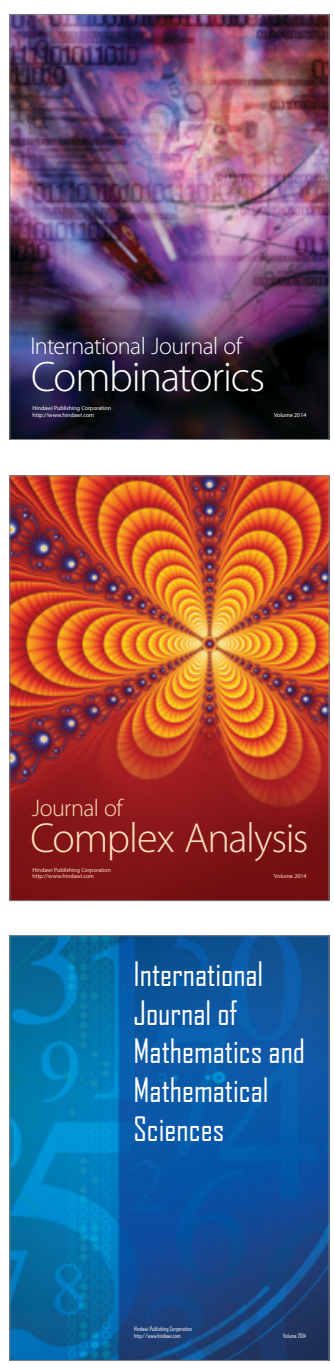
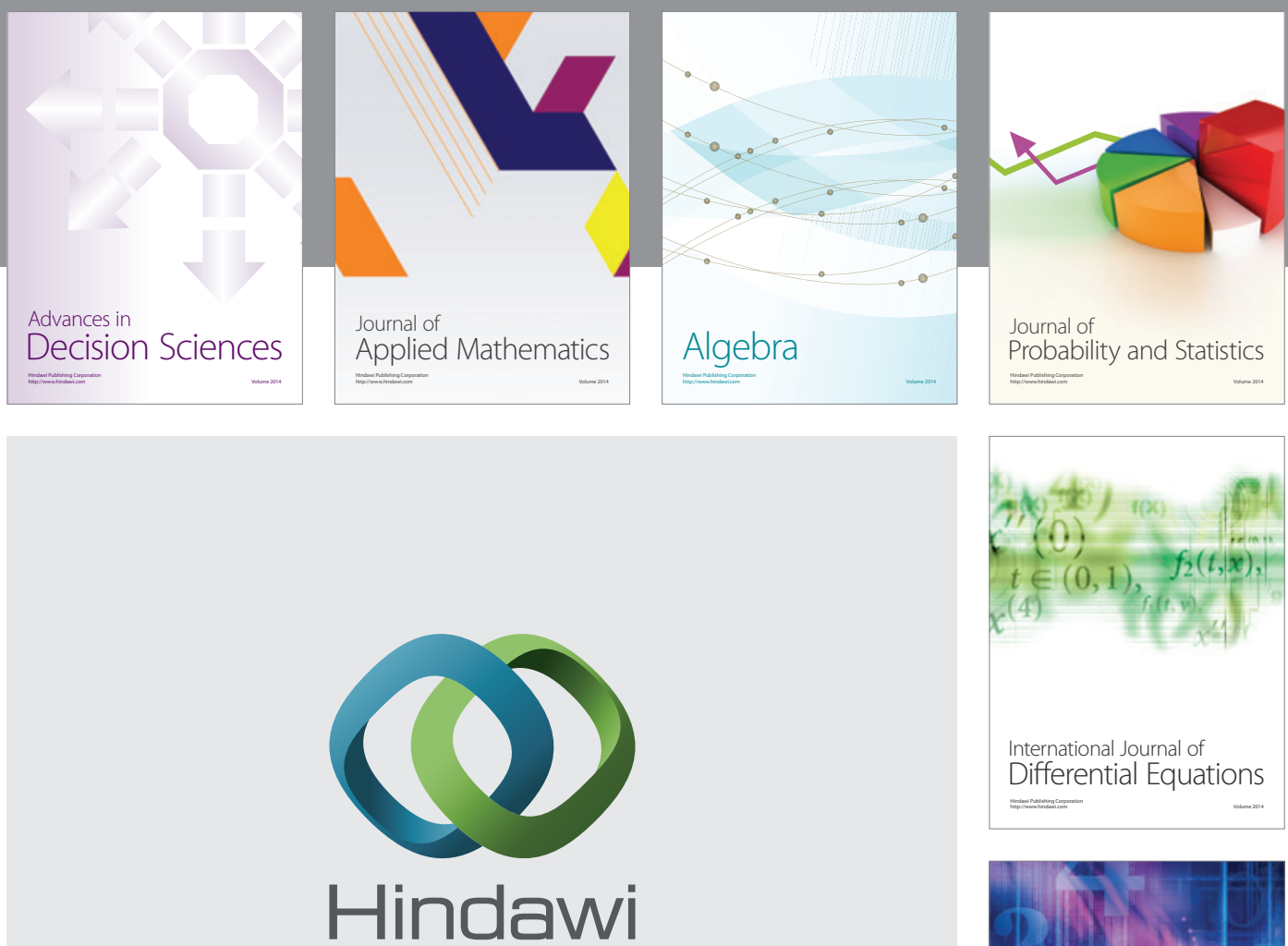

Submit your manuscripts at http://www.hindawi.com
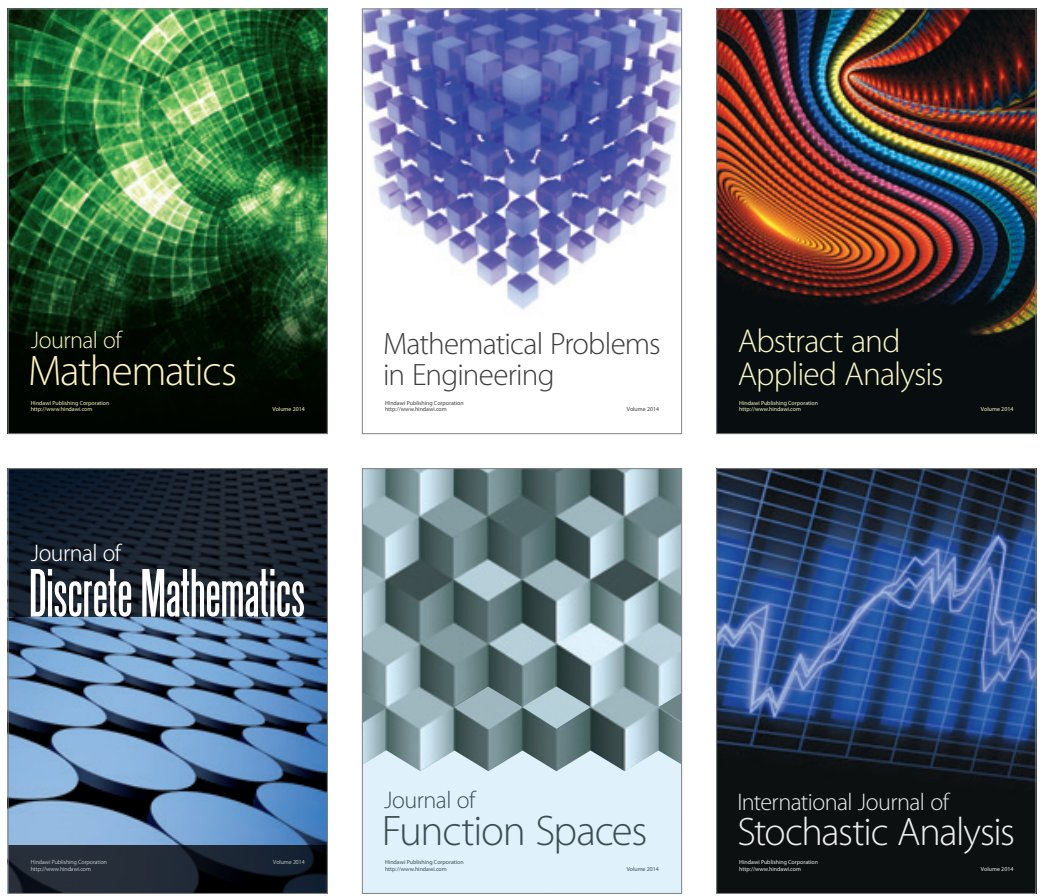

Journal of

Function Spaces

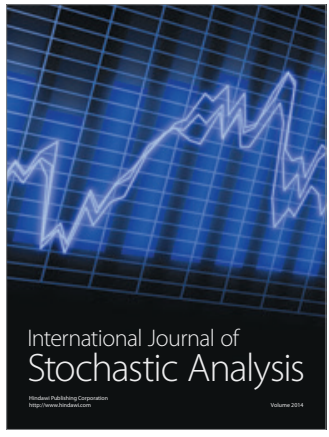

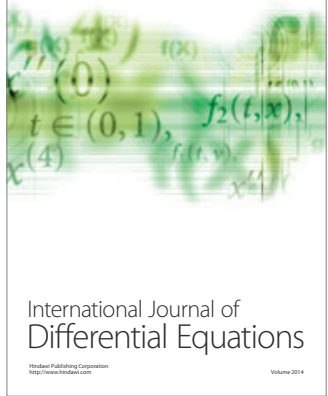
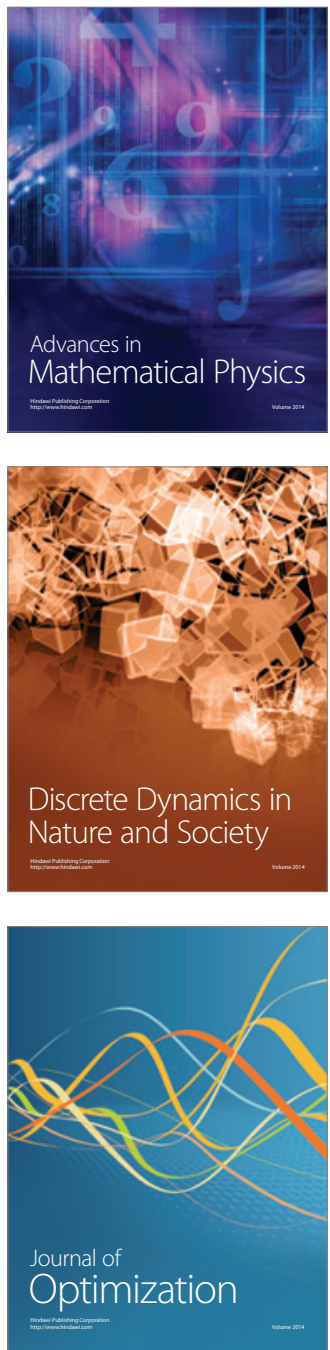